\title{
Climate change, extreme weather events, air pollution and respiratory health in Europe
}

\author{
M. De Sario ${ }^{1}$, K. Katsouyanni ${ }^{2}$ and P. Michelozzi ${ }^{1}$
}

Affiliations:

'Dept of Epidemiology, Lazio Regional Health Service, Rome, Italy.

${ }^{2}$ National and Kapodistrian University of Athens, Athens, Greece.

\section{Correspondence:}

M. De Sario, Dept of Epidemiology, Lazio Regional Health Service, Via di Santa Costanza, 53, 00198 Rome, Italy. E-mail: m.desario@deplazio.it

ABSTRACT Due to climate change and other factors, air pollution patterns are changing in several urbanised areas of the world, with a significant effect on respiratory health both independently and synergistically with weather conditions; climate scenarios show Europe as one of the most vulnerable regions. European studies on heatwave episodes have consistently shown a synergistic effect of air pollution and high temperatures, while the potential weather-air pollution interaction during wildfires and dust storms is unknown. Allergen patterns are also changing in response to climate change, and air pollution can modify the allergenic potential of pollens, especially in the presence of specific weather conditions. The underlying mechanisms of all these interactions are not well known; the health consequences vary from decreases in lung function to allergic diseases, new onset of diseases, exacerbation of chronic respiratory diseases, and premature death. These multidimensional climate-pollution-allergen effects need to be taken into account in estimating both climate and air pollution-related respiratory effects, in order to set up adequate policy and public health actions to face both the current and future climate and pollution challenges.

@ERSpublications

Climate change, extreme weather events and air pollution affect respiratory health: the evidence reviewed http://ow.ly/mmh5g

This article has supplementary material available from www.erj.ersjournals.com

Received: May 102012 | Accepted after revision: Dec 292012 | First published online: Jan 112013

Support statement: This work was funded within the European Union PHASE project (EAHC contract number: 20101103).

Conflict of interest: None declared.

Copyright @ERS 2013 


\section{Introduction}

The continuous increase in anthropogenic emissions of carbon dioxide and other greenhouse gases following the industrial revolution is dramatically changing climate, both overall and at regional level. As in other parts of the world, Europe has experienced a progressive warming ( $+0.90^{\circ} \mathrm{C}$ for 1901-2005) and an increase in mean precipitation, except in some regions (i.e. the Mediterranean region) that are becoming arid $[1,2]$. Climate scenarios for the next century predict that the warming will be associated with more frequent, more intense and longer lasting heatwaves, especially in Southern and Eastern Europe, and also in areas not currently susceptible to such events $[2,3]$. This will be paralleled by an increase in the intensity of short duration precipitation events (1-2 days) in regions such as the Mediterranean, where a decrease in mean precipitation is also expected [2]. The higher intensity of rainfall events will increase the likelihood of floods, especially flash floods, throughout Europe, while the occurrence of heatwaves and droughts will increase the risk of wildfires and desertification, notably around the Mediterranean basin [2].

In urban areas, climate change is likely to influence outdoor air pollution levels because the generation and dispersion of air pollutants, such as ozone and particulate matter, depend in part on local patterns of temperature, wind, solar radiation and precipitation [4]. In some regions, air quality is projected to further worsen due to the increased frequency of wildfires that cause the release of gaseous and particulate pollutants into the atmosphere. In addition, changes in wind patterns and desertification will modify the long-range transport of pollutants emitted by human activities and biomass burning [4].

Changing patterns of disease are occurring in response to changing environmental conditions. It is widely recognised that air pollution has a significant impact on human health, with a great burden on respiratory diseases, particularly asthma, rhinosinusitis, chronic obstructive pulmonary disease (COPD) and respiratory tract infections [5]. Changes in climate are expected to further aggravate the effect of air pollution on these diseases. Prompted by these scenarios, the American Thoracic Society and the European Respiratory Society have recently expressed their concern about the threat posed by air pollution and climate change on respiratory disease $[6,7]$. Current and future impacts on respiratory mortality and morbidity deriving from changes in climate as well as from trends in air pollutants are, therefore, a priority for the researchers, respiratory clinicians and policy-makers agenda.

This review summarises the scientific evidence on the effects of climate-related hazards on respiratory health from epidemiological studies. Specifically, we considered those climate events which may be influenced most by climate change and for which climate conditions are interlinked with air quality: temperature extremes, wildfires and dust storms. The conceptual framework for these interactions is summarised in figure 1. Pathogenetic mechanisms, vulnerable population subgroups and policy implications are discussed and research needs are identified.

\section{Climate change and air quality}

Climate change and air pollution are intrinsically connected since greenhouse gases and air pollutants originate from the same source, fossil fuel combustion [8-10]. In fact, combustion processes emit both greenhouse gases, like carbon dioxide $\left(\mathrm{CO}_{2}\right)$, methane $\left(\mathrm{CH}_{4}\right)$ and nitrous oxide $\left(\mathrm{N}_{2} \mathrm{O}\right)$, and air pollutants, like particulate matter $(\mathrm{PM})$, sulfur dioxide $\left(\mathrm{SO}_{2}\right)$, nitrogen dioxide $\left(\mathrm{NO}_{2}\right)$ and carbon monoxide $(\mathrm{CO})$.

At both a global and a regional level, now and in the future, climate change and air pollution trends counterbalance in determining air quality: on the one hand, a reduction in anthropogenic emissions,

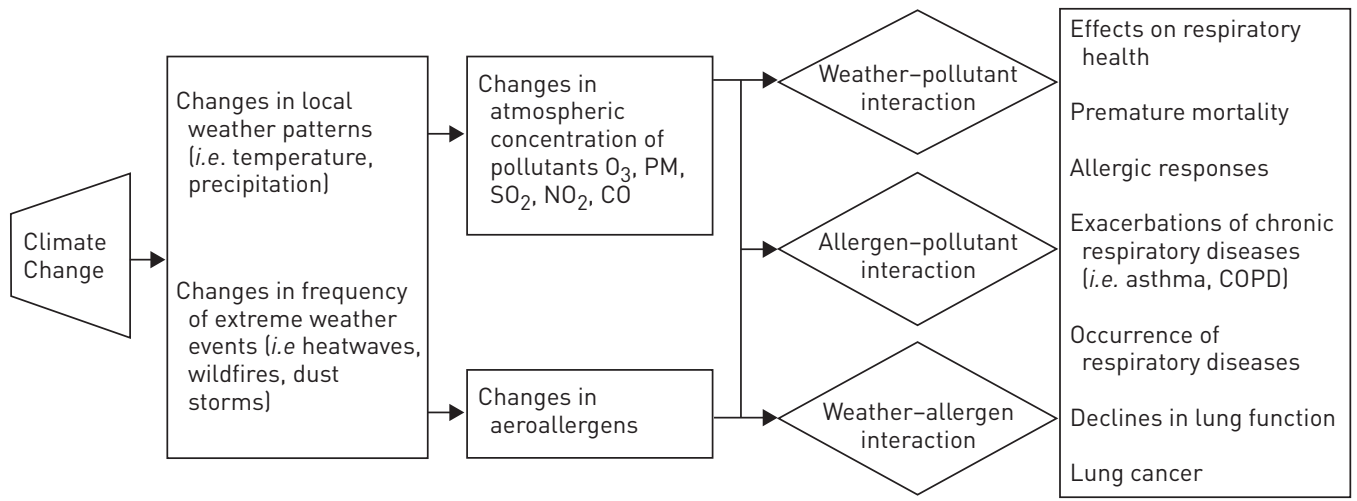

FIGURE 1 Climate change: its influence on extreme weather events, air pollution and aeroallergens, and effects on respiratory health. PM: particulate matter; COPD: chronic obstructive pulmonary disease. 
resulting from the implementation of the emission control legislation adopted in each country and energetic sector improvements; on the other hand, climate change effects, in most cases leading to an increase in pollution levels [10].

The correlation between climate and air quality is noteworthy for ozone. Ozone levels are directly driven by weather since ozone-generating photochemical reactions of air pollutants (nitrogen oxides; methane; volatile organic compounds, VOCs) need high temperatures and bright sunshine, conditions typical of summer months [11]. High temperatures are often associated with dry weather conditions, which significantly contribute to high ozone levels during heatwaves through a drought stress on vegetation that inhibits stomatal uptake of ozone $[8,12]$. Anthropogenic emissions of ozone precursors will decline in industrialised countries but not in the emerging economies. Hemispheric background ozone concentrations will increase due to a higher frequency of forest fires [11]. Considering climate change scenarios, a large climate change-related ozone increase is expected in Southern European regions that will overcome the beneficial reduction in ozone precursor anthropogenic emissions in these countries [11].

Climatic factors affect particulate matter concentrations to different extents depending on the PM chemical components [8]. On the one hand, high temperature results in an increase in sulfate aerosols due to faster $\mathrm{SO}_{2}$ oxidation, and on the other, it brings about a reduction in nitrate PM concentrations due to increased gas phase transition [8]. However, under climate change the nitrate burden is predicted to increase along with all other aerosol species, except sulfates [13]. Over Europe, the predicted increase in overall aerosol concentrations will be by $20-40 \mu \mathrm{g} \cdot \mathrm{m}^{-3}$ relative to the present-day values [13]. Changes will be driven by precipitation changes since wet deposition represents the primary PM sink, but also by increments in water vapour that increase oxidation of $\mathrm{SO}_{2}$ and sulfate concentrations. Air stagnation conditions represent another important factor that will increase PM concentrations in polluted regions [4, 8]. Climate changerelated increase in wildfires will also influence particulate levels [14, 15]; an increased fire risk in Mediterranean countries is expected, especially in areas with high forest cover $[4,16]$. The 2003 heatwave in Europe is emblematic since it was associated with both record wildfires and high PM levels [8]. During wildfires the main concern is fine particles (particles with a diameter $<2.5 \mu \mathrm{m}, \mathrm{PM} 2.5$ ) since they have a longer lifetime (of the order of days) and may be carried long distances from their source regions [17]. Future PM concentrations are also driven by the long-range transport of dust aerosols. The long-range transport of pollutants emitted by human activities, burning biomass and dust will also be influenced by future climate changes, due to changes in wind patterns and desertification [4].

Another important link between climate and air quality is that primary products of combustion processes (i.e. carbon monoxide, non-methane VOCs, nitrogen oxides, sulfur dioxide, black carbon and organic carbon aerosols) and some secondary pollutants (i.e. ozone) have the potential to increase global warming directly or indirectly [18]. Carbon monoxide, non-methane VOCs and nitrogen oxides cause a reduction in the oxidant power of the atmosphere increasing the lifetime of methane, one of the most important warming agents and a precursor to ozone [18]. Nitrate particles, as well as organic carbon aerosols, instead have a cooling effect on the climate. Sulfur dioxide partly converts to sulfate particles, which also have cooling potential, and partly reacts with black carbon, which has a strong warming effect [18]. Wildfires may directly contribute to global warming since they emit large quantities of greenhouse gases (i.e. carbon monoxide, carbon dioxide and methane) [19].

\section{Respiratory health effects}

Since the 1990s, an extensive European collaboration has been set up through the European Union (EU) funded research programmes in the field of air pollution (APHEA, APHEIS, AIRNET, APHEKOM) and climate change (cCASHh, PHEWE, EuroHEAT, CIRCE) [20]. These studies have substantially contributed to current epidemiological knowledge on the short-term health effects of air pollution and high temperatures or heatwaves in Europe, and to the formulation of the World Health Organization guidelines [21] and EU air pollution standards. Several of these projects also specifically investigated the synergy between air pollution, high temperature exposure and heatwave events (PHEWE, EuroHEAT, CIRCE) [22]. The ongoing EU project PHASE (Public Health Adaptation Strategies to Extreme weather events) will provide further insights into the synergy between air pollution and extreme weather events (e.g. heatwaves and cold spells) and an innovative aspect will be investigation of their environmental consequences (floods, wildfires) that are projected to increase with predicted climate change [23].

\section{Air pollution}

Respiratory diseases are on the rise worldwide, especially allergic diseases such as asthma and rhinitis $[24,25]$. This trend has been documented in both industrialised and developing countries, but was greater in regions where prevalence was previously low $[24,25]$. However, geographical differences have emerged from studies comparing areas at different urbanisation levels or Eastern and Western European countries, 
providing evidence of a higher frequency of allergic respiratory diseases in westernised and more urbanised areas $[26,27]$. The causes of such large heterogeneity on both the temporal and geographical scales should be searched for in environmental exposures, since genetic factors cannot change so rapidly to such an extent; outdoor air pollution is one possible explanation of the observed trends [28]. Primary (i.e. nitrogen oxides and VOCs) and secondary pollutants (i.e. ozone) have been associated with a wide range of respiratory health effects, including exacerbations of diseases in subjects already affected by chronic respiratory illnesses, such as asthma and COPD, that account for repeated hospitalisations and emergency department visits for the underlying disease, declines in lung function, asthma attacks, emergency room visits, hospital admissions, premature mortality and, possibly, the occurrence of new respiratory problems, i.e. new-onset asthma $[5,6,21,29,30]$. Despite the decreasing current trends in anthropogenic air pollution levels in the USA and Europe (although not uniformly) [31], there is strong evidence that air pollutants have an effect on respiratory health even at the low levels actually measured [29]. In Europe since the 1990s, the APHEA multicentre project has identified and quantified the short-term health effects of these air pollution levels (see online supplementary table). Immediate effects on mortality (lag 0-1 days) associated with a $10 \mu \mathrm{g} \cdot \mathrm{m}^{-3}$ increase in pollutant were $0.4 \%$ for nitrogen dioxide [32], $0.6 \%$ for PM10 [33], $0.8 \%$ for black smoke and $1.1 \%$ for ozone [34]. The delayed effects are even greater, 4.2\% for PM10 (lag 0-40) [35], and 3.4\% for ozone (lag 0-20) [36]; these pollutants had the most prolonged lagged effects on respiratory mortality compared to total or cardiovascular mortality $[35,36]$. Air pollutants have also an effect on hospital admissions for specific causes, i.e. $10 \mu \mathrm{g} \cdot \mathrm{m}^{-3}$ increase of PM10 and sulfur dioxide is associated with $0.5-1.5 \%$ increase in admissions for asthma and COPD in specific age groups [37-39].

\section{Outdoor temperature}

European projects have documented that respiratory health is largely affected not only by air pollution but also by weather conditions, especially in the population over 75 years old (table 1). During summer, each degree Celsius increase in maximum apparent temperature (a combined indicator of temperature and humidity) above a city specific threshold level (ranging from 23 to $29^{\circ} \mathrm{C}$ ) is related to $\sim 7 \%$ increase in daily respiratory deaths [40]. A smaller, but still significant effect, has been observed on respiratory hospital admissions, around 3-5\% [41]. The effect of extreme events, i.e. heatwaves, is much larger, accounting for an increase in respiratory mortality during each heatwave day ranging from $12.1 \%$ to $61.3 \%$ [42]. Effects of high temperature and heatwaves are greater in Mediterranean rather than north continental European cities [40-42].

Cold temperatures are also a cause for concern for respiratory health, with a $3-4 \%$ increase in daily mortality and hospitalisations for respiratory causes in the population over 75 years old for each degree Celsius decrease in minimum temperature or minimum apparent temperature. In this case, northern populations seem to be at a greater risk than southern ones [43,44]. Results from the available studies suggest an effect of heat and heatwaves and cold temperature on mortality, hospital admissions, admissions in geriatric units and emergency visits for specific respiratory diseases, such as asthma, COPD and pneumonia, although the results are limited and somewhat contrasting and more evidence is needed [45].

Other weather conditions, i.e. specific variables such as humidity and rainfall, but also combinations of several meteorological variables (i.e. temperature, humidity, visibility, cloud cover, air pressure and wind speed) defined as "synoptic air masses", have been associated with increases in mortality and morbidity but specific evidence for respiratory causes is scarce and there is no clear evidence that these variables may have an independent effect apart from temperature [46-52].

\section{Synergy (effect modification) of air pollution and temperature effects}

Several European time-series and case-crossover studies have provided indirect evidence (i.e. that effects are stronger in the warm season or in warmer cities) suggestive of interactions between air pollution and heat, although other explanations are consistent with these results [53-56]. The multicentre APHEA study found ozone effects on respiratory mortality only during summer [34], while single-city studies provided contrasting results, with a significant effect on respiratory deaths all year round [57], and a positive association with physician consultations for asthma and with paediatric asthma hospital admissions only in the summer months $[58,59]$. A study in Cyprus showed an ozone effect on respiratory admissions that was stronger in the warm season [60].

The APHEA project also provided evidence of seasonal differences in the effect of pollutants other than ozone, i.e. black smoke and sulfur dioxide, whose effects on respiratory mortality were also found to be higher in summer [53]. Other studies found similar [55, 61], or contrasting findings [57, 59, 62]. The APHEA study provided evidence of effect modification not only by season but also according to typical temperatures for the area; the greatest PM10 effects were in the warmest cities but no result for respiratory 


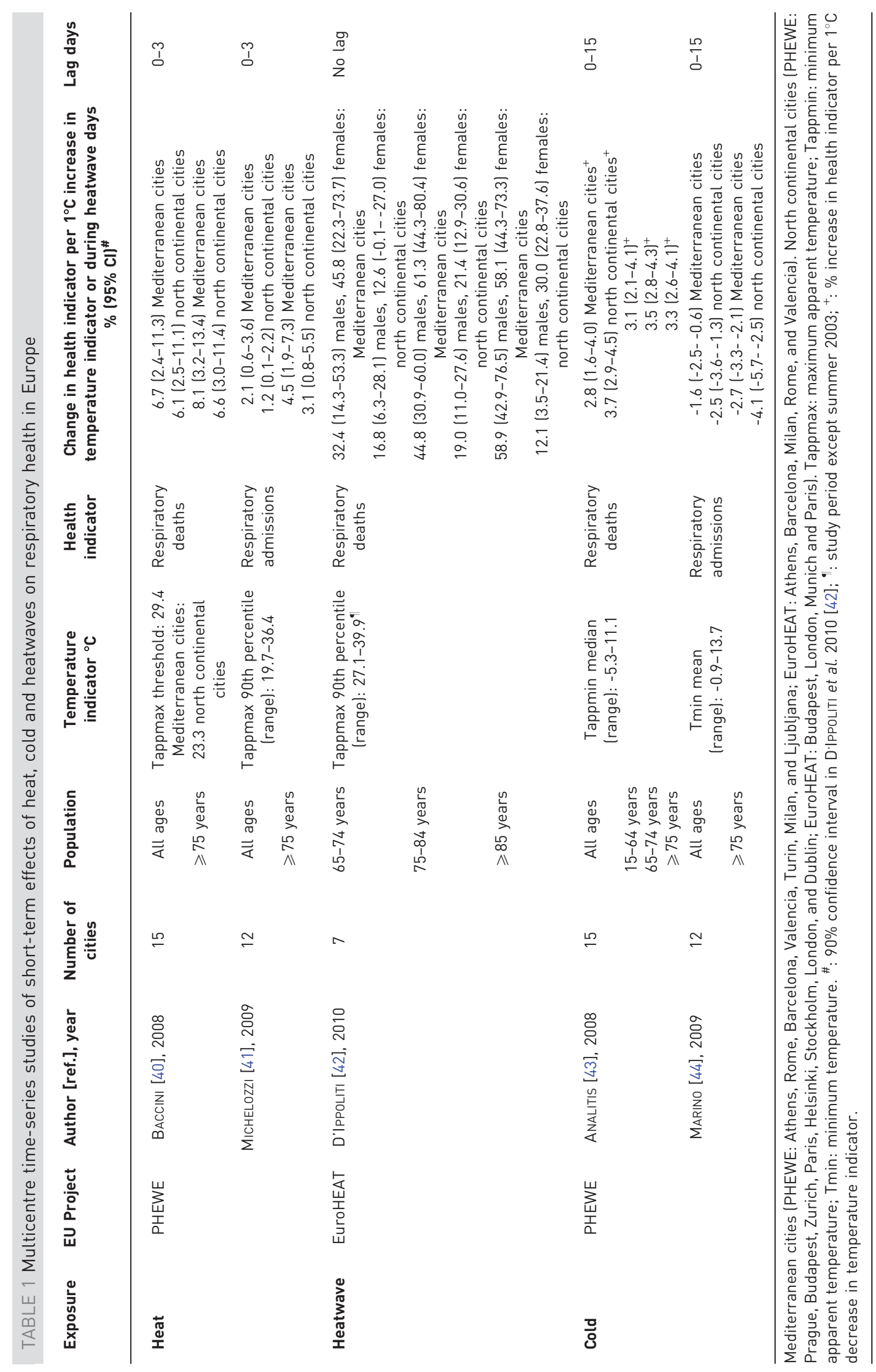


causes was available [63]. On the other side of the relationship, a study from Greece found a greater effect of heatwaves in Athens where pollution levels were higher than in all other urban areas [64].

Several studies provided consistent evidence of a synergy between the two exposures [65-77], with only one study showing no evidence of interaction [78]. In all these studies the potential interaction between air pollution health effects and high or low temperature was tested through interaction terms or by means of a stratified analysis in time-series and case-crossover analyses. Among studies carried out in a European country (table 2), three studies [55, 76, 79] analysed the synergistic effect on mortality for respiratory causes. In the UK study, the ozone effect on respiratory mortality during hot days corresponded to a rate ratio of 1.009 , while the pollutant had no effect on ordinary days (rate ratio $=1.000$ ), but the ozone-heat interaction was significant only in London and ozone-heat interactions were greatest in those aged $<75$ years [76]. In Italy, an effect of PM10 on respiratory mortality was found only for temperatures above the 50th percentile compared to no effect on days with a temperature below the 50th percentile [55]. The study of CARDER et al. [79], carried out in Scotland, instead found a positive interaction between cold temperatures and black smoke concentrations on respiratory mortality. Other European studies analysed total mortality; they were focused on specific heatwave episodes [64, 66-69] or on both warm and cold periods [70] and provided evidence of a significant interaction between high temperature and pollutants, mainly ozone. Two multicentre studies suggested that the synergistic effect may vary among cities according to local climate characteristics, activity patterns and physical adaptation $[69,76]$.

The synergy between temperature and air pollution has been also evaluated in multicentre European studies analysing the other side of effect modification: air pollution levels modifying the health effect of temperature or heatwaves (table 3) [22]. For ozone, there is consistent evidence of interaction with heat or

TABLE 2 Interaction of weather variables on air pollution effects: epidemiological studies in European cities published since 1990 s

Author [ref.], year Country, period Study design Population Health indicator $\begin{gathered}\text { Method to detect } \\ \text { interaction }\end{gathered}$

Pattenden [76], 2010

CARDer [79], 2008

NAWROT [70], 2007

FiLLEUL [69], 2006

DEAR [68], 2005

SARTOR $[66,67], 1995$, 1997

KatsouyanNI [64], 1993 Athens (Greece) Summer 1987

15 conurbations
(UK)

Summer

1993-2003

Scotland (UK)

(3 cities)

1981-2001

Italy (9 cities)

1997-2004

Flanders

(Belgium)

1997-2003

France (9 cities) Summer 2003

\section{France (12 cities) \\ Summer 2003 \\ Belgium}

Summer 1994
Time-series All ages

and specific
causes)

$$
\begin{aligned}
& \text { Mortality (total } \\
& \text { and specific } \\
& \text { causes) }
\end{aligned}
$$

Time-series All ages

Mortality Itotal and specific causes)

\section{Case-cross- $>35$ years} over

Time-series

Episode

analysis

Episode

analysis

Episode analysis
All ages Mortality (total)

All ages Mortality (total)

$>65$ years Mortality (total)

Thears Mortality (total)

All ages Mortality (total)
Interaction terms

Interaction terms

Interaction terms; stratification by temperature

Stratification by season/ temperature

Joint response surfaces

Interaction terms Stratification by temperature

Interaction terms
Positive interaction of ozone and high temperature, significant only in London

No evidence of effect modification by season

Significant positive interaction of black smoke and low temperature on respiratory causes

Significant positive interaction of PM10 and summer/high

temperatures for natural or CVD; heterogeneity for respiratory causes

Significant positive interaction of PM10 and summer for natural, CVD and respiratory causes

Interaction between PM10 and high temperature on effect on total mortality

Positive interaction of ozone and high temperature heterogeneous among cities

Significant positive interaction of ozone and high temperature

Significant positive interaction of ozone and high temperature at levels $>20^{\circ} \mathrm{C}$

Significant positive interaction of $\mathrm{SO}_{2}$ and high temperature; suggestive interaction for ozone and smoke

PM10: particulate matter with a diameter $<10 \mu \mathrm{m}$; CVD: cardiovascular disease. 
heatwave effects on mortality from natural causes in the elderly, but no evidence of interaction on respiratory mortality [22]. Concerning PM10, the study carried out before the year 2000 did not find any interaction with temperature, while the more recent time-series studies showed a significant effect modification. In particular, PM10 significantly modified the heatwave effect on mortality for respiratory causes in Mediterranean cities (65-74 years) [22] and there is a suggestion of interaction with effect of high temperature on this group of diseases. For PM10 there is also evidence of effect modification of temperature effect during the cold season, with a lower cold effect on respiratory mortality on high pollution days [22].

Overall, results from studies of temperature-air pollution interactions suggest that this topic cannot be disregarded when studying temperature or air pollution effects regarding respiratory causes, since the true magnitude of the associations may be underestimated. Results differ by pollutant considered and study area, suggesting that the underlying mechanisms are driven by local conditions. Moreover, the evaluation of effect modification presents specific methodological challenges. In many studies stratification can provide quantitative estimates, but results are dependent on the selection of cut-offs for strata. In contrast, the use of more flexible models, i.e. joint pollutant-temperature response surface on health outcomes, has the disadvantage of not providing parametric estimates $[29,74]$.

Other weather conditions, such as humidity, have been suggested to interact with air pollutant effects. Low absolute humidity may increase the effect of total suspended particles on hospitalisations for COPD [80]. However, it should be noted that absolute humidity is very strongly correlated with temperature, so in essence this finding may be reflecting temperature effects. Humidity was also found to be a significant effect modifier of the effect of air pollutants on mortality, as found in the $29 \mathrm{EU}$ cities included in the APHEA2 project [63]; the observed effect of PM10 increased as humidity levels decreased. Another remarkable type of interaction is that from air masses and air pollutants. In a study in Birmingham, UK, two winter air masses that were associated with increased admission rates for respiratory causes (continental anticyclonic gloom and continental anticyclonic fine and cold) were also favourably associated with high PM10 levels [47].

\section{Air pollution and wildfire}

Wildfire smoke is a complex mixture of particles, liquids and gaseous compounds. The effect of fires is usually measured with respect to fine PM (PM2.5) levels, since it predominates in the smoke [81-83], and is thought to be responsible for the greater part of the observed health effects. Fine particles are created directly during the combustion process and also formed later from the emitted gases through condensation and atmospheric chemical reactions [17]. During wildfires, levels of PM are usually well above the background pollution level for the area and usually beyond air quality standards (24 h mean PM10: $50 \mu \mathrm{g} \cdot \mathrm{m}^{-3}$; 1-year average mean PM2.5: $25 \mu \mathrm{g} \cdot \mathrm{m}^{-3}$ ), over $500 \mu \mathrm{g} \cdot \mathrm{m}^{-3}$ in some cases [17, 81-83]. The extreme event is identified according to a certain threshold, i.e. the 99th percentile of particulate distribution. This allows extreme events to be distinguished from situations in which background pollution sources predominate.

Since wildfires are usually episodes of short duration, the length of the exposure may be too short to detect the health effects, as well as to evaluate their impact on air quality [81-83]. As in the case of urban air pollution, during wildfire episodes the respiratory system is particularly affected: increases in mortality, hospitalisations, emergency department visits for all respiratory causes and for specific diseases (mainly asthma, COPD, lower and upper respiratory diseases), asthma and COPD exacerbations, respiratory symptoms and decreases in lung function are observed, both in healthy subjects and in asthmatic and COPD patients [81-83]. Most evidence on the short-term effects of wildfires comes from the USA, Asia and Australia, while only a few studies have been carried out in the European context [84-87], despite the fact that wildfires are common in the Mediterranean forests of Greece, Spain, Italy and Portugal [16]. In the study carried out in Athens, Greece, the occurrence of a large forest fire (one which burnt more than $30000000 \mathrm{~m}^{2}$ ), lead to a significant short-term effect on mortality for respiratory causes in the elderly [84]; this effect could be explained only in part by an increase in ambient particle concentrations. A survey carried out in Barcelona, Spain during the 2003 wildfires on healthy 6- to 19-year-olds documented increased respiratory and eye symptoms with increasing frequency of wildfire smoke exposure; associations were stronger in the subjects with lowest lung function [86]. Increases in hospital attendances for respiratory conditions and asthma were documented during the fires which surrounded Vilnius, Lithuania in 2002 [87].

Studies on wildfire health effects commonly adjust for meteorological variables. Since during wildfire events ambient temperature is usually high, there is also a potential for interaction as demonstrated by the concomitance of heatwave and wildfire conditions in summer 2010 in Russia and the huge impact on the population in terms of adverse effects on respiratory health [88]. This interaction could be explained, at the point of emissions, by changes in smoke constituents driven by temperature, sunlight, water vapour and 
TABLE 3 Interaction of air pollution on heat or heatwave-related effects: evidence from European studies

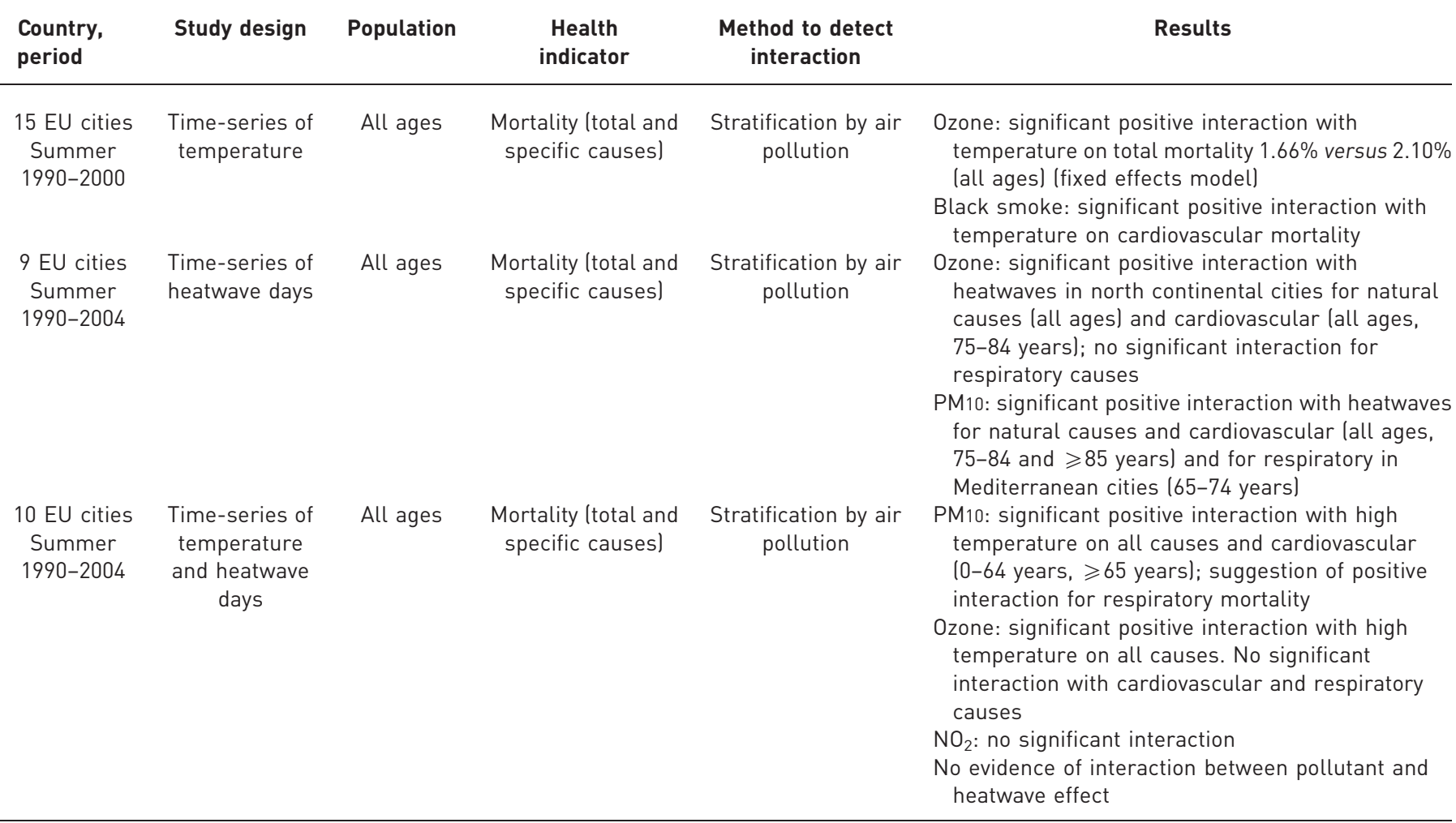

EU: European Union; PM10: particulate matter with a diameter $<10 \mu \mathrm{m}$. Data taken from Katsouyanni et al. [22] and A. Annalitis (University of Athens, Athens, Greece; personal communication).

interaction with other pollutants [17]. Furthermore, meteorological conditions influence smoke dispersion and transportation [19]. The long range transport of smoke plumes for thousands of kilometres is a public health concern also in European countries as, for example, in Finland where long-range transported PM episodes that originate from wildfires in Russia, Belarus, Ukraine and the Baltic countries are common [85]. However, no study, to date, has evaluated the possible effect modification of weather on PM-related effects during wildfire. Other wildfire consequences include visibility impairment and ozone generation [89]; these factors may also interact with PM levels in determining health effects [87].

Overall, the available evidence suggests an effect of wildfires on respiratory health. The greatest methodological challenge in these studies regards the estimate of exposure; in most cases PM measurements from air quality monitoring stations are used, but these are limited to specific points and are, therefore, not well representative of actual exposure. The more recent approach of using burnt areas from satellite data seems to be more effective in identifying areas at risk. Moreover, wildfires are rare events and their effect depends also on the local context; therefore, results are not easily generalisable and, to date, there is no consensus to estimate exposure taking into account the dispersion process of smoke [90].

\section{Air pollution and desert dust storms}

Desert regions throughout the world are known to be the source of dust storms that are driven by weather conditions and transported over long distances, with North Africa (the Sahara) being the main contributing area (over 50\%) [91-93]. Dust particles derive from the earth's crust and affect air quality, in particular PM10 and coarse particulate (PM2.5-10) levels [91-93]. For example, during Saharan events PM10 concentrations exceed the EU daily limit value, surpassing $100 \mu \mathrm{g} \cdot \mathrm{m}^{-3}$ or $150 \mu \mathrm{g} \cdot \mathrm{m}^{-3}$ at rural stations $[60,91,93]$. As with wildfire smoke, dust storms may also be transported over thousands kilometres, changing composition and concentration of pollutants on the way, and following specific trajectories that can be back-derived by mathematical models. These episodes can cause PM concentration peaks in areas with low local emissions that are very far from the emission sources, including rural background areas [94].

The Mediterranean and Europe are particularly affected by dust storms from North Africa, which have significant impact on air quality and human health $[91,93]$. The growing evidence in these regions suggests a greater effect of PM on dust days than on non-dust days [59, 60, 95-103], in particular on mortality or 
hospital admissions for respiratory causes (table 4) [59, 96-103]. On the contrary, no effect was found in a study in Cyprus [60], while a greater effect on non-dust days was found in Athens [98]. Overall, associations are more coherent as regards coarse particles (PM2.5-10) than for PM2.5 and PM10. Only studies outside Europe, mainly from Asia and Australia, evaluated dust storms effects on specific respiratory diseases, such as pneumonia, rhinitis, COPD and asthma; however, evidence is still limited and rather contrasting, especially regards hospital admissions for these diseases [91, 93].

As in the case of wildfires, the meteorological context is important in the case of dust storms; cyclone and anticyclone systems may favour the long-range transport of dust and convective activity and rainfall may cause the abatement of dust air masses [94]. In addition, dust storms tend to occur in contemporary with high ambient temperatures and high ozone levels [93]. Despite these important links, the interaction between weather variables and dust storms has not yet been analysed. However, the effect modification of particulates by Saharan dust days was robust both to ozone adjustment and to the exclusion of extremely warm days [97]. To the best of our knowledge, only one study has quantified the direct health effect of dust storms providing evidence for an increase in asthma and respiratory admissions, especially in the younger population [104].

The study of the effect of dust storms presents specific methodological challenges [91, 93]. First, the low frequency of dust days restricts analysis of cause-specific mortality or morbidity. Moreover, due to their nature the occurrence and intensity of dust intrusions is strongly linked to the specific local context. For example, Saharan dust storms mostly affect the Eastern Mediterranean Basin regions and their frequency, intensity, seasonality, as well as the years considered and local climate conditions affect the dust composition and, consequently, health effects. Similar to wildfires, the definition of the dust event is critical. Usually dust days are defined based on overcoming a specific threshold for PM, or on the basis of backtrajectory analysis considered to be a marker of dust transport from the source regions. In urban areas dust events may be underestimated due the presence of other, mainly anthropogenic, sources of dust [93].

\section{Mechanisms and vulnerable subgroups}

The respiratory system is the main target of gases, aerosols and particles present in air pollution. A wide range of effects on the respiratory system are triggered by environmental toxicants, from reversible local responses to long-term chronic effects: local irritation, direct cellular damage to the epithelium of respiratory airways, allergic responses (i.e. asthma) and cancer. The underlying mechanisms are different for the different pollutants. Ozone provokes oxidative damage to the respiratory epithelium, resulting in lung inflammation, decrements in lung function, worsening of respiratory tract symptoms and increased airway reactivity [105]. Particulate matter, via enhanced oxidative stress, may disrupt lung endothelial cell barrier integrity, thereby inducing lung dysfunction and adverse cardiopulmonary outcomes [106].

Not only air pollution but also high and low temperatures have a strong effect on respiratory health as discussed above. Underlying mechanisms are better understood for cold than for heat. Cold temperature may affect respiratory health in different ways and seems to affect not only susceptible but also healthy subjects. Breathing cold air causes the cooling of nasal and bronchial mucosa, seriously impairing ciliary motility and consequently reducing the immune system's resistance to respiratory infections [107, 108]. Exposure to cold air may also increase the number of granulocytes and macrophages in the lower airways in healthy subjects [109] and induce bronchoconstriction [110,111], suggesting that cold exposure could be involved in the pathogenesis of the asthma-like condition. Part of the increase in respiratory outcomes during cold periods may also be attributed to cross-infections from increased indoor crowding during winter [112].

In contrast to observed cold-related effects, the health consequences deriving from exposure to heat seem to be greater in patients affected by chronic respiratory diseases. In these patients, it may be hypothesised that thermoregulatory responses to heat stress, particularly those involving the respiratory system, may be ineffective at dissipating excess heat, thus increasing their risk of developing heat stress conditions such as dehydration and heatstroke. However, this hypothesis is still not supported by experimental studies [113]. A different pathway linking heat exposure to respiratory health outcomes involves the clinical course of heatrelated illnesses such as heatstroke. In patients with heatstroke, acute lung inflammation and damage might occur [114] and heat may trigger a series of physiological changes in the lung leading to a severe respiratory distress syndrome $[41,115]$. Recent experimental evidence suggests that exposure to chronic heat stress could increase the susceptibility of animals to highly pathogenic respiratory viruses by reducing local immunity in the respiratory tract, i.e. the number of pulmonary alveolar macrophages [116]. Other weather conditions, particularly humidity, may adversely affect respiratory health but their role is still unclear. Some studies showed that in both healthy and asthmatic subjects humidity may decrease lung capacity and increase airways resistance $[117,118]$, while in others humidity did not influence non-specific airway 
TABLE 4 Interaction of dust storms on air pollution effects: evidence from European studies

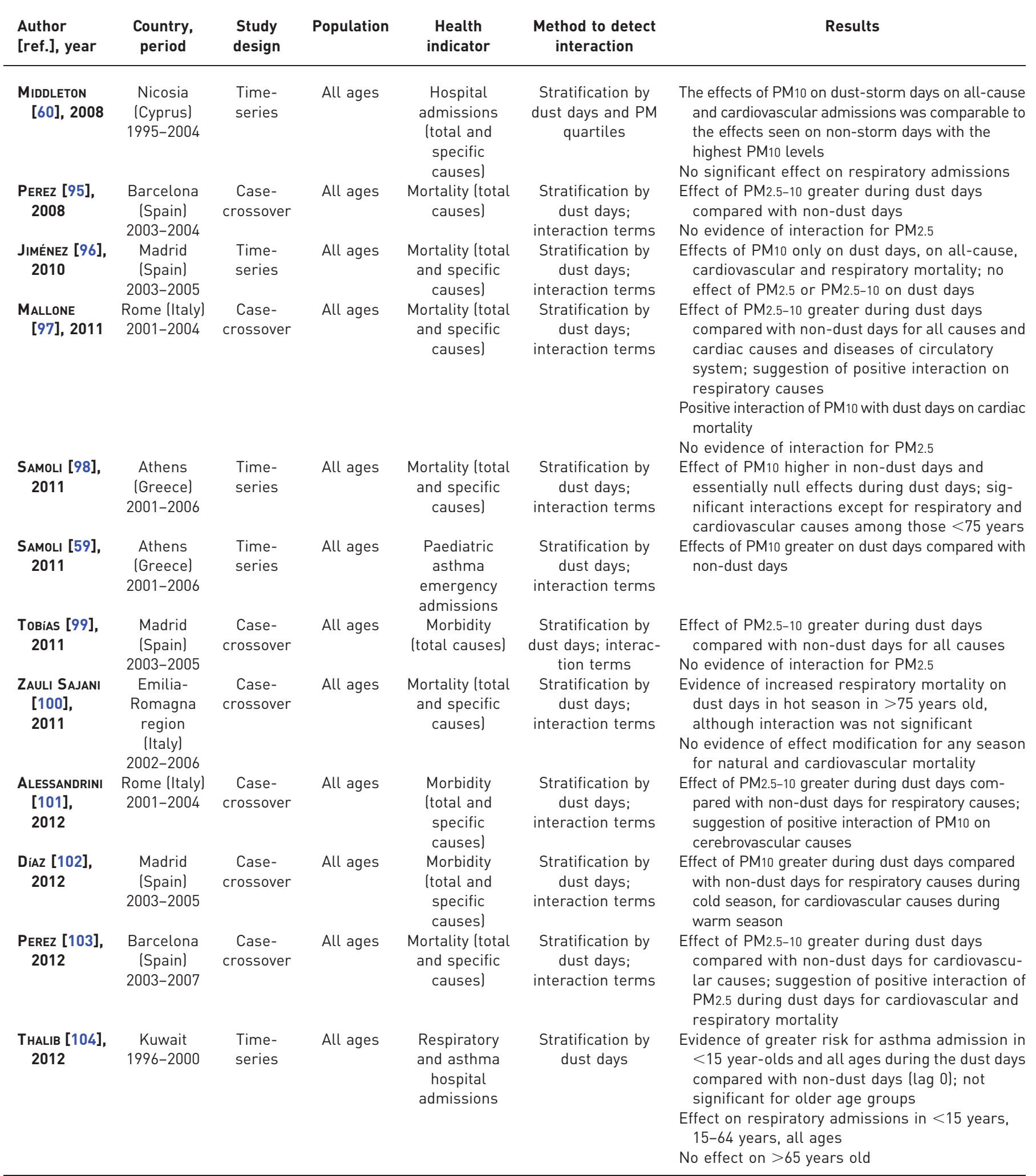

PM: particulate matter; PM10: particulate matter with a diameter $<10 \mu \mathrm{m}$; PM2.5-10: particulate matter with a diameter $\geqslant 2.5 \mu \mathrm{m}$ and $<10 \mu \mathrm{m}$; PM2.5: particulate matter with a diameter $<2.5 \mu \mathrm{m}$. 
hyperresponsiveness [119]. Humidity may also indirectly affect respiratory allergic diseases by influencing atmospheric levels of aeroallergens, with low humidity favouring release, dispersion and transport of pollen $[120,121]$. Extreme weather events, such as thunderstorms, may trigger asthma epidemics by inducing pollen grain rupture by osmotic shock, which releases respirable allergens into the atmosphere [120, 121].

The evidence of a synergistic effect between air pollution and temperature can have different explanations. Since the respiratory surfaces are the primary route by which air pollutants enter the body, the activation of thermoregulatory responses at pulmonary level during prolonged heat exposure may augment the total intake of airborne pollutants due to the increase in ventilation rate and lung volumes $[122,123]$. It has also been suggested that variations in the sources of air pollution and meteorological factors can result in changes in characteristics of the air pollution mixture across seasons [70, 124, 125]. However, in an experimental study modifications in PM components were not able to explain the seasonal difference in PM effects, which could instead be related to the highest prevalence of allergens in spring and summer influencing the onset and severity of allergic diseases [126]. The higher effects of pollutants observed in summer than in winter might also be due to the lower exposure measurement error during summer, as a consequence of more time spent outdoors or, especially for particles, due to a more similar composition between indoor and outdoor pollutants $[55,70,124,127,128]$. Another hypothesis is that the lower winter mortality for infectious diseases resulting in a lower mortality among the elderly, i.e. among those most susceptible, has the consequence of a larger pool of susceptible people at risk of air pollution effects the following summer [70, 124, 127]. To explain the interaction between pollutant and low temperature [79], a hypothesised mechanism is that the cold-related impairment of respiratory mucociliary function may inhibit the clearance of pollutants [107, 108].

Meteorological factors such as temperature may also influence the interaction between allergens and air pollution in producing adverse respiratory effects since air pollution-related damage to the respiratory epithelium increases airway permeability stimulating allergen-induced responses and absorption of pollutants to the surface of pollen grains may modify their allergenic potential [120, 121]. Also humidity may modify air pollution effects on respiratory health. Airways of individuals suffering from respiratory diseases seem to be protected against the effect of particles by high humidity, probably due to the reduced number of particles [80].

Mechanisms explaining the respiratory effects of wildfires and dust storms are mainly linked to the air pollution associated with these events. Particulate matter is the predominant air pollutant in fire smoke, which also contains gases including carbon monoxide, nitrous oxides, polycyclic aromatic hydrocarbons, VOCs, ozone and nitrogen dioxide [81-83]. Wood smoke particles have been shown to activate systemic and pulmonary inflammation in healthy human subjects [91, 93]. There is still insufficient evidence to establish whether wildfire PM may have a greater effect than urban background PM [17, 81-83].

However, smoke particulate is probably different in composition with respect to urban PM, having a greater concentration of PM that can accumulate in the lungs. An in vivo experiment found that responses to wood smoke consist of higher inflammatory and cytotoxic responses than those triggered by urban particulate matter [129]. Apportionment techniques are expected to provide important insights into whether fire components are less or more toxic than the same constituents from fossil fuel burning and to clarify the underlying mechanisms.

In the case of dust storms, not only the chemical composition of particles but also its biological content is the probable causative agent of respiratory health effects [91-93]. In particular, coarse particles may have greater allergenic and inflammatory properties, absorbing to their surface pollens and microorganisms such as bacteria and fungi, as well as endotoxins, which are components of the bacterial wall that can cause respiratory and systemic inflammatory responses, and exacerbate lung disease [91-93]. This hypothesis is coherent with recent evidence of an increase in infectious diseases (i.e. meningitis) on dust days [93]. Moreover, in their long-range travel dust particles may absorb metals, pesticides and industrial products mixing with the anthropogenic emissions of industrial regions (e.g. North African). Inhaling these compounds can cause lung irritation, reducing lung capacity through activation of oxidative stress pathways $[91,93]$. As in the case of wildfires, chemical speciation and toxicity studies may clarify whether dust particles are more or less toxic than urban PM, considering that dust may also contribute to PM concentrations other than interacting with airborne particulate pollution from local sources.

\section{Vulnerable subgroups}

The links between climate and air pollution on human health are complicated by the presence in a population of specific subgroups at greater risk of adverse health effects (i.e. vulnerable subgroups) owing to a series of environmental, individual and population characteristics. According to the Intergovernmental Panel on Climate Change, vulnerability is defined as a function of the level of exposure (character, 
magnitude and rate of weather event), of the level of the susceptibility and the adaptive capacity of populations [130]. Several climate-sensitive subgroups have been identified: heat and heatwaves have a stronger impact on people with impaired physiological and behavioural responses to heat due to age, sex, socioeconomic factors, pre-existing chronic diseases, use of certain medications and environmental conditions (i.e. lack of air conditioning) but the pattern of susceptibility factors is population-specific and may vary over time $[113,131]$. Regarding cold exposure, indoor climatic conditions seem to confer a greater vulnerability, especially in the elderly [132, 133], while there is contrasting evidence of a socioeconomic gradient of risk $[134,135]$. Less known are the susceptibility factors to other extreme events like wildfires and dust storms. Subjects with asthma and COPD, females and children are more likely to be affected by wildfires [17, 81-83]; children, the elderly, people of low income and persons with cardiovascular and respiratory disease may be more susceptible to the effects of dust storms [91-93].

The individual characteristics that identify subgroups at greater risk due to air pollution are pollutantspecific. Susceptible subjects to particulate matter comprise the elderly, people of low socioeconomic status and COPD and cardiovascular disease patients [136, 137], while regarding ozone there is contrasting evidence on whether some subgroups have a greater risk of adverse effects than the general population $[138,139]$.

\section{Research needs in the context of respiratory health}

Considering climate change scenarios, quantifying the effect estimates on respiratory health and identifying vulnerable population subgroups are crucial research areas to carry out health impact assessments to understand future impacts and to support decision-makers and the healthcare community in the fight against this global environmental threat [6].

Table 5 summarises for each climate hazard the main respiratory outcomes and the population subgroups for which there is evidence of association from epidemiological studies; research gaps and future expected impacts under climate change are also highlighted. Overall, every climate hazard appears to have a significant impact on the respiratory system, although evidence on specific respiratory diseases and specific age groups is still limited. At European level, there is scarce epidemiological evidence on the effects of extreme cold and wildfires. Multicentre studies are lacking in the analysis of rare and local-extent episodes, such as dust storms and wildfires. The ongoing PHASE [23] and MEDPARTICLES [140] multicentre projects will provide further insights on both these hazardous exposures. Pre-existing respiratory diseases are important vulnerability factors to both temperature and air pollution effects. Since vulnerability factors are specific for each climate hazard and may vary across populations and over time, more research is needed, in particular on younger age groups and children, but also on other population segments, such as low socioeconomic groups.

Considering future impacts on respiratory diseases, population ageing, increased prevalence of chronic diseases and the socioeconomic transitions which are currently ongoing in several countries will probably increase the portion of the population at risk [141, 142]. Almost all climate hazards will worsen under climate change, as will the related disease burden. The only beneficial effect will be the reduction in coldrelated effect (i.e. respiratory infections) due to warmer winters [142]. However, due to the complexity of the above mentioned climate-air quality interactions, a great deal of uncertainty remains regarding future trends of climate and pollutants. Research is needed to increase the modelling capability to better understand the interplay between human activities, air pollution and regulatory requirements, climate policy, economic factors, and to predict future trends of air pollutants, accounting for uncertainty and variability in projections of global change. Advances in modelling capability can derive from disease surveillance integrated with air pollution, weather and climate data and from combining ecological approaches (time-series studies) with spatial methods to produce a more complete evaluation of health effects, taking into account both geographical and temporal variations. From a public health point of view, since health professionals have joined the climate change debate late [143], they are urged to develop modelling skills in relation to climate change, particularly by combining climate models with ecological and health outcome models for projecting disease dynamics under various climate scenarios.

\section{Policy implications}

Due to the close climate and air pollution interlinkages, climate change policies need to be integrated with air quality policies to be effective. Moreover, mutual benefits can be achieved: actions to mitigate climate change by reducing greenhouse gas emissions may help reduce air pollution since they involve mainly changes in the transport and energy sectors which are also driving pollutant sinks and, at the same time, clean air measures can reduce anthropogenic emissions that are important contributors to global warming. Benefits of climate policies on air pollution have been evaluated for Europe [144]. Although there were 
TABLE 5 Synthesis of evidence on respiratory outcomes by climate hazard: vulnerable subgroups, research gaps and future impacts

Climate hazard

Study outcomes

Study population groups

Research gaps

Children, adults, elderly

heatwaves

All respiratory diseases (mortality, HA)
Pneumonia (mortality, HA, geriatric admissions) COPD (mortality, HA) Asthma (mortality, HA, prevalence)
Adults, elderly

Elderly

Children, adults
Effect on specific diseases/morbidity outcomes

Effect on children and young age groups Effect on low socioeconomic subgroups Short and long-term harvesting effect Population health impacts Pathogenetic mechanisms
Cold temperature/ cold spells

Wildfires

Dust storms

Temperature-
pollutant
interaction

All respiratory diseases (mortality,

HA, GP visits)

Lower respiratory tract disease (mortality, GP visits) Asthma (ED visits, GP visits) Upper respiratory tract disease (GP visits)

All respiratory diseases (mortality, HA/rehospitalisa-

tion, GP visits, ED visits)

Asthma (ED visits, outpatient attendance, decreased lung function, asthma symptoms:

Upper respiratory tract disease loutpatient

attendance, respiratory symptoms]

COPD (ED visits, HA, exacerbation of symptoms)

Lower respiratory tract

disease (hospital admissions,

emergency room visits)

All respiratory diseases (mortality,

HA, ED visits)

COPD (ED visits, HA)

Asthma (mortality, paediatric

admissions, HA, ED visits

decreases lung function,

asthma exacerbations)

Pneumonia (HA)

Rhinitis (HA, clinical visits)

All respiratory diseases Imortality,

HA, ED visits)

Asthma (ED visits)
Children, adults, elderly

Elderly

Children, adults Elderly

Children, elderly

Children, adults, asthmatics

Children

Adults, elderly, COPD patients

Children, elderly

Children, adults, elderly

Elderly

Children, adults, asthmatics

Children, adults elderly Children

Adults, elderly

Children
Effect on specific diseases/morbidity outcomes

Effect on younger age groups Effect on low socioeconomic subgroups To identify vulnerability factors li.e. indoor)

Effect on populations where cold spells are rare

Population health impacts

To identify vulnerability factors

Evidence from European studies

Evidence from multicentre studies

Interaction with urban air pollution

Interaction with heatwaves

Population health impacts

Pathogenetic mechanism

Effect on specific diseases/morbidity outcomes

Evidence from multicentre studies

Evidence from studies in areas most exposed

To identify vulnerability factors Interaction with weather conditions

Effect of consecutive days of dust storms Identify particles chemical composition Population health impacts

Toxicological and pathogenetic mechanisms

Interaction between air pollutants and cold temperature

Interaction of temperature with specific pollutants

Effect on specific diseases/morbidity outcomes

Pathogenetic mechanisms

\section{1st century impacts under climate change scenarios}

Increase in effects due to the higher frequency of hot extremes and heatwaves

Reduced effects due to change in adaptive capacity of populations Increase in vulnerable population due to aging, also in developing countries Increase in vulnerable population due to increasing prevalence of chronic respiratory diseases in industrialised countries

Change in heat-related effects in different socioeconomic scenarios Increase in infectious diseases in children under five in developing countries

Reduced cold-related effects due to warmer winters in industrialised countries

Increase in vulnerable population due

to aging, also in developing countries

Increase in vulnerable population due to prevalence of chronic respiratory diseases in industrialised countries

Increase in effects due to the higher frequency of wildfires Increase in long-range transport of air pollutants due to changes in wind patterns and to increases in desertification

Increase in vulnerable population due to aging, also in developing countries Increase in vulnerable population due to prevalence of chronic respiratory diseases in industrialised countries

Increase in long-range transport of air pollutants due to changes in wind patterns and to increases in desertification

Increase in vulnerable population due to aging, also in developing countries Increase in vulnerable population due to prevalence of chronic respiratory diseases in industrialised countries Increase in infectious diseases in children under 5 years in developing countries

Increase potential for interaction due to increases in specific pollutants and in the frequency of hot extremes and heatwaves

HA: hospital admissions; COPD: chronic obstructive pulmonary disease; GP: general practitioner; ED: emergency department. 
limitations in data availability, especially in relation to the scenario datasets and modelling uncertainties, benefits resulted for all investigated emission scenarios, with the scenarios based on energy efficiency strategies leading to larger benefits [144].

At the European level, although stringent emission targets have been made (i.e. to reduce domestic greenhouse gas emissions by $80 \%$ by 2050 compared to 1990 levels), the greatest reductions in greenhouse gas emissions have been achieved only as an indirect effect of the current economic crisis [145]. To accomplish greenhouse gas reduction targets, countries need to reach the convergence between resource productivity and efficiency. However, energy efficiency improvements, i.e. switching to fuel with a lowcarbon content but higher price, leads to increases in environmental inequality posing major risks to disadvantaged groups, for example due to inadequate housing and heating systems. To cope with economic and climate changes, European countries need to develop a more comprehensive policy framework that integrates climate policy, industrial policy, employment and social policy [145].

\section{Conclusions}

Climate and climate change are modifying air pollution effects on respiratory health in several ways: climate variations are predicted to influence the start, duration and intensity of the pollen season, to increase the frequency and intensity of heatwaves, heavy precipitation events (i.e. thunderstorms) and wildfires, and to raise long-range transport of air pollutants and allergens [4].

To face both the current and future climate and pollution challenges, adequate policy and public health actions are needed, taking into account the interrelationships between the two hazardous exposures. Since climate change is a global problem, with the worst consequences occurring not in developed but in developing countries, global actions are needed. Policies to reduce greenhouse gas emissions need to be established, especially in countries which hold the greatest emission burden. In parallel, developing countries are increasingly affected by urban air pollution due to rapid economic and population growth $[146,147]$. The way forward to face both these challenges needs the multisectorial collaboration of epidemiologists, climatologists, respiratory and allergy specialists, policy makers and public health professionals to share the heavy responsibility of guiding the world through the climate crisis and making the environment sustainable for future generations.

\section{References}

1 Gualdi S, Navarra A. Scenari climatici nel bacino mediterraneo. [Climate scenarios in the Mediterranean region.]. Forest@ 2005; 2: 19-30.

2 Alcamo J, Moreno JM, Nováky B, et al. Europe. In: Climate Change 2007: Impacts, Adaptation and Vulnerability. Contribution of Working Group II to the Fourth Assessment Report of the Intergovernmental Panel on Climate Change. Parry ML, Canziani OF, Palutikof JP, et al., eds. Cambridge, Cambridge University Press, 2007; pp. 541-580.

3 Meehl GA, Tebaldi C. More intense, more frequent, and longer lasting heat waves in the 21st century. Science 2004; 305: 994-997.

4 Denman KL, Brasseur G, Chidthaisong A, et al. Couplings between changes in the climate system and biogeochemistry. In: Climate Change 2007: The Physical Science Basis. Contribution of Working Group I to the Fourth Assessment Report of the Intergovernmental Panel on Climate Change. Solomon S, Qin D, Manning M, et al., eds. Cambridge, Cambridge University Press, 2007; pp. 499-587.

5 American Thoracic Society. What constitutes an adverse health effect of air pollution? Official statement of the American Thoracic Society. Am J Respir Crit Care Med 2000; 161: 665-673.

6 Ayres JG, Forsberg B, Annesi-Maesano I, et al. Climate change and respiratory disease: European Respiratory Society position statement. Eur Respir J 2009; 34: 295-302.

7 Pinkerton KE, Rom WN, Akpinar-Elci M, et al. An official American Thoracic Society workshop report: climate change and human health. Proc Am Thorac Soc 2012; 9: 3-8.

8 Jacob DJ, Winner DA. Effect of climate change on air quality. Atmospheric Environment 2009; 43: 51-63.

9 Noyes PD, McElwee MK, Miller HD, et al. The toxicology of climate change: environmental contaminants in a warming world. Environ Int 2009; 35: 971-986.

10 Dennekamp M, Carey M. Air quality and chronic disease: why action on climate change is also good for health. N S W Public Health Bull 2010; 21: 115-121.

11 Engardt M, Bergström R, Andersson C. Climate and emission changes contributing to changes in near-surface ozone in Europe over the coming decades: results from model studies. Ambio 2009; 38: 452-458.

12 Ordonez C, Mathis H, Furger M, et al. Changes of daily surface ozone maxima in Switzerland in all seasons from 1992 to 2002 and discussion of summer 2003. Atmos Chem Phys 2005; 5: 1187-1203.

13 Liao H, Chen WT, Seinfeld JH. Role of climate change in global predictions of future tropospheric ozone and aerosols. J Geophys Res 2006; 111: D12304.

14 Krawchuk MA, Moritz MA, Parisien MA, et al. Global pyrogeography: the current and future distribution of wildfire. PLoS One 2009; 4: e5102.

15 Spickett JT, Brown HL, Rumchev K. Climate change and air quality: the potential impact on health. Asia Pac J Public Health 2011; 23: Suppl. 2, 37S-45S.

16 Moriondo M, Good P, Durao R, et al. Potential impact of climate change on fire risk in the Mediterranean area. Climate Research 2006; 31: 85-95.

17 Naeher LP, Brauer M, Lipsett M, et al. Woodsmoke health effects: a review. Inhal Toxicol 2007; 19: 67-106. 
Smith KR, Jerrett M, Anderson HR, et al. Public health benefits of strategies to reduce greenhouse-gas emissions: health implications of short-lived greenhouse pollutants. Lancet 2009; 374: 2091-2103.

19 Viswanathan S, Eria L, Diunugala N, et al. An analysis of effects of San Diego wildfire on ambient air quality. J Air Waste Manag Assoc 2006; 56: 56-67.

20 Forastiere F, De Sario M, Michelozzi P. Il contributo italiano ai programmi di ricerca dell'Unione europea sui rischi per la salute associati al clima e all' inquinamento ambientale. [The Italian contribution to EU research programs on health effects of air pollution and climate in a changing environment.]. Epidemiol Prev 2010; 34: 39-46.

21 World Health Organization Europe. Air quality guidelines. Global update for 2005. Particulate matter, ozone, nitrogen dioxide and sulfur dioxide. Copenhagen, WHO Regional Office for Europe, 2006.

22 Katsouyanni K, Analitis A. Investigating the synergistic effects between meteorological variables and air pollutants: results from the European PHEWE, EUROHEAT and CIRCE projects. Epidemiology 2009; 20 : S264.

23 Health Protection Agency. Public Health Adaptation Strategies to Extreme weather events (PHASE). www.hpa.org.uk/ Topics/EmergencyResponse/ExtremeWeatherEventsAndNaturalDisasters/PHASE/ Date last accessed: June 28, 2013.

24 Pearce N, Ait-Khaled N, Beasley R, et al. Worldwide trends in the prevalence of asthma symptoms: phase III of the International Study of Asthma and Allergies in Childhood (ISAAC). Thorax 2007; 62: 758-766.

25 Björkstén B, Clayton T, Ellwood P, et al. Worldwide time trends for symptoms of rhinitis and conjunctivitis: Phase III of the International Study of Asthma and Allergies in Childhood. Pediatr Allergy Immunol 2008; 19: 110-124. von Mutius E. The rising trends in asthma and allergic disease. Clin Exp Allergy 1998; 28: 45-49.

Douwes J, Pearce N. Asthma and the westernization 'package'. Int J Epidemiol 2002; 31: 1098-1102.

Anderson HR. Air pollution and trends in asthma. Ciba Found Symp 1997; 206: 190-202.

Ren C, Tong S. Health effects of ambient air pollution-recent research development and contemporary methodological challenges. Environ Health 2008; 7: 56.

30 Jerrett M, Shankardass K, Berhane K, et al. Traffic-related air pollution and asthma onset in children: a prospective cohort study with individual exposure measurement. Environ Health Perspect 2008; 116: 1433-1438.

31 Granier C, Bessagnet B, Bond T, et al. Evolution of anthropogenic and biomass burning emissions of air pollutants at global and regional scales during the 1980-2010 period. Climatic Change 2011; 109: 163-190.

32 Samoli E, Aga E, Touloumi G, et al. Short-term effects of nitrogen dioxide on mortality: an analysis within the APHEA project. Eur Respir J 2006; 27: 1129-1138.

33 Analitis A, Katsouyanni K, Dimakopoulou K, et al. Short-term effects of ambient particles on cardiovascular and respiratory mortality. Epidemiology 2006; 17: 230-233.

34 Gryparis A, Forsberg B, Katsouyanni K, et al. Acute effects of ozone on mortality from the air pollution and health: a European approach project. Am J Respir Crit Care Med 2004; 170: 1080-1087.

35 Zanobetti A, Schwartz J, Samoli E, et al. The temporal pattern of respiratory and heart disease mortality in response to air pollution. Environ Health Perspect 2003; 111: 1188-1193.

36 Samoli E, Zanobetti A, Schwartz J, et al. The temporal pattern of mortality responses to ambient ozone in the APHEA project. J Epidemiol Community Health 2009; 63: 960-966.

37 Sunyer J, Atkinson R, Ballester F, et al. Respiratory effects of sulphur dioxide: a hierarchical multicity analysis in the APHEA 2 study. Occup Environ Med 2003; 60: e2.

38 Atkinson RW, Anderson HR, Sunyer J, et al. Acute effects of particulate air pollution on respiratory admissions: results from APHEA 2 project. Air Pollution and Health: a European Approach. Am J Respir Crit Care Med 2001; 164: 1860-1866.

39 Atkinson RW, APHEA 2 Project. Acute effects of air pollution on admissions: reanalysis of APHEA 2. Am J Respir Crit Care Med 2004; 169: 1257-1258.

40 Baccini M, Biggeri A, Accetta G, et al. Heat effects on mortality in 15 European cities. Epidemiology 2008; 19: 711-719.

41 Michelozzi P, Accetta G, De Sario M, et al. High temperature and hospitalizations for cardiovascular and respiratory causes in 12 European cities. Am J Respir Crit Care Med 2009; 179: 383-389.

42 D'Ippoliti D, Michelozzi P, Marino C, et al. The impact of heat waves on mortality in 9 European cities: results from the EuroHEAT project. Environ Health 2010; 9: 37.

43 Analitis A, Katsouyanni K, Biggeri A, et al. Effects of cold weather on mortality: results from 15 European cities within the PHEWE project. Am J Epidemiol 2008; 168: 1397-1408.

44 Marino C, de'Donato F, Michelozzi P, et al. Effects of cold weather on hospital admissions: results from 12 European cities within the PHEWE project. Epidemiology 2009; 20: S67-S68.

45 Turner LR, Barnett AG, Connell D, et al. Ambient temperature and cardiorespiratory morbidity: a systematic review and meta-analysis. Epidemiology 2012; 23: 594-606.

46 Jamason PF, Kalkstein LS, Gergen PJ. A synoptic evaluation of asthma hospital admissions in New York City. Am J Respir Crit Care Med 1997; 156: 1781-1788.

47 McGregor GR, Walters S, Wordley J. Daily hospital respiratory admissions and winter air mass types, Birmingham, UK. Int J Biometeorol 1999; 43: 21-30.

48 Braga A, Zanobetti A, Schwartz J. The time course of weather related deaths. Epidemiology 2001; 12: 662-667.

49 Keatinge WR, Donaldson GC. Mortality related to cold and air pollution in London after allowance for effects of associated weather patterns. Environ Res 2001; 86: 209-216.

50 Schwartz J, Samet J, Patz J. Hospital admissions for heart disease: the effects of temperature and humidity. Epidemiology 2004; 15: 755-761.

51 Abe T, Tokuda Y, Ohde S, et al. The relationship of short-term air pollution and weather to ED visits for asthma in Japan. Am J Emerg Med 2009; 27: 153-159.

52 Mireku N, Wang Y, Ager J, et al. Changes in weather and the effects on pediatric asthma exacerbations. Ann Allergy Asthma Immunol 2009; 103: 220-224.

53 Zmirou D, Schwartz J, Saez M, et al. Time-series analysis of air pollution and cause-specific mortality. Epidemiology 1998; 9: 495-503.

54 Anderson HR, Bremner SA, Atkinson RW, et al. Particulate matter and daily mortality and hospital admissions in the west midlands conurbation of the United Kingdom: associations with fine and coarse particles, black smoke and sulphate. Occup Environ Med 2001; 58: 504-510.

55 Stafoggia M, Schwartz J, Forastiere F, et al. Does temperature modify the association between air pollution and mortality? A multicity case-crossover analysis in Italy. Am J Epidemiol 2008; 167: 1476-1485. 
56 Stieb DM, Szyszkowicz M, Rowe BH, et al. Air pollution and emergency department visits for cardiac and respiratory conditions: a multi-city time-series analysis. Environ Health 2009; 8: 25.

57 Anderson HR, Ponce de Leon A, Bland JM, et al. Air pollution and daily mortality in London: 1987-92. BMJ 1996; 312: 665-669.

58 Hajat S, Haines A, Goubet SA, et al. Association of air pollution with daily GP consultations for asthma and other lower respiratory conditions in London. Thorax 1999; 54: 597-605.

59 Samoli E, Nastos PT, Paliatsos AG, et al. Acute effects of air pollution on pediatric asthma exacerbation: evidence of association and effect modification. Environ Res 2011; 111: 418-424.

60 Middleton N, Yiallouros P, Kleanthous S, et al. A 10-year time-series analysis of respiratory and cardiovascular morbidity in Nicosia, Cyprus: the effect of short-term changes in air pollution and dust storms. Environ Health 2008; 7: 39.

61 Tramuto F, Cusimano R, Cerame G, et al. Urban air pollution and emergency room admissions for respiratory symptoms: a case-crossover study in Palermo, Italy. Environ Health 2011; 10: 31.

62 Touloumi G, Samoli E, Katsouyanni K. Daily mortality and "winter type" air pollution in Athens, Greece - a time series analysis within the APHEA project. J Epidemiol Community Health 1996; 50: Suppl. 1, S47-S51.

63 Katsouyanni K, Touloumi G, Samoli E, et al. Confounding and effect modification in the short-term effects of ambient particles on total mortality: results from 29 European cities within the APHEA2 project. Epidemiology 2001; 12: 521-531.

64 Katsouyanni K, Pantazopoulou A, Touloumi G, et al. Evidence for interaction between air pollution and high temperature in the causation of excess mortality. Arch Environ Health 1993; 48: 235-242.

65 Ren C, Williams GM, Mengersen K, et al. Does temperature modify short-term effects of ozone on total mortality in 60 large eastern US communities? An assessment using the NMMAPS data. Environ Int 2008; 34: 451-458.

66 Sartor F, Snacken R, Demuth C, et al. Temperature, ambient ozone levels, and mortality during summer 1994, in Belgium. Environ Res 1995; 70: 105-113.

67 Sartor F, Demuth C, Snacken R, et al. Mortality in the elderly and ambient ozone concentration during the hot summer, 1994, in Belgium. Environ Res 1997; 72: 109-117.

68 Dear K, Ranmuthugala G, Kjellström T, et al. Effects of temperature and ozone on daily mortality during the August 2003 heat wave in France. Arch Environ Occup Health 2005; 60: 205-212.

69 Filleul L, Cassadou S, Médina S, et al. The relation between temperature, ozone, and mortality in nine French cities during the heat wave of 2003. Environ Health Perspect 2006; 114: 1344-1347.

70 Nawrot TS, Torfs R, Fierens F, et al. Stronger associations between daily mortality and fine particulate air pollution in summer than in winter: evidence from a heavily polluted region in western Europe. J Epidemiol Community Health 2007; 61: 146-149.

71 Qian Z, He Q, Lin HM, et al. High temperatures enhanced acute mortality effects of ambient particle pollution in the "oven" city of Wuhan, China. Environ Health Perspect 2008; 116: 1172-1178.

$72 \mathrm{Hu} \mathrm{W}$, Mengersen K, McMichael A, et al. Temperature, air pollution and total mortality during summers in Sydney, 1994-2004. Int J Biometeorol 2008; 52: 689-696.

73 Mohr LB, Luo S, Mathias E, et al. Influence of season and temperature on the relationship of elemental carbon air pollution to pediatric asthma emergency room visits. J Asthma 2008; 45: 936-943.

74 Ren C, Williams GM, Mengersen K, et al. Temperature enhanced effects of ozone on cardiovascular mortality in 95 large US communities, 1987-2000: assessment using the NMMAPS data. Arch Environ Occup Health 2009; 64: 177-184.

75 Lin CM, Liao CM. Temperature-dependent association between mortality rate and carbon monoxide level in a subtropical city: Kaohsiung, Taiwan. Int J Environ Health Res 2009; 19: 163-174.

76 Pattenden S, Armstrong B, Milojevic A, et al. Ozone, heat and mortality: acute effects in 15 British conurbations. Occup Environ Med 2010; 67: 699-707.

77 Li G, Zhou M, Cai Y, et al. Does temperature enhance acute mortality effects of ambient particle pollution in Tianjin City, China. Sci Total Environ 2011; 409: 1811-1817.

78 Hales S, Salmond C, Town GI, et al. Daily mortality in relation to weather and air pollution in Christchurch, New Zealand. Aust NZ J Public Health 2000; 24: 89-91.

79 Carder M, McNamee R, Beverland I, et al. Interacting effects of particulate pollution and cold temperature on cardiorespiratory mortality in Scotland. Occup Environ Med 2008; 65: 197-204.

80 Leitte AM, Petrescu C, Franck U, et al. Respiratory health, effects of ambient air pollution and its modification by air humidity in Drobeta-Turnu Severin, Romania. Sci Total Environ 2009; 407: 4004-4011.

81 Finlay SE, Moffat A, Gazzard R, et al. Health impacts of wildfires. PLoS Curr 2012; 4: e4f959951cce2c.

82 Boman BC, Forsberg AB, Järvholm BG. Adverse health effects from ambient air pollution in relation to residential wood combustion in modern society. Scand J Work Environ Health 2003; 29: 251-260.

83 Dennekamp M, Abramson MJ. The effects of bushfire smoke on respiratory health. Respirology 2011; 16: 198-209.

84 Analitis A, Georgiadis I, Katsouyanni K. Forest fires are associated with elevated mortality in a dense urban setting. Occup Environ Med 2012; 69: 158-162.

85 Hanninen O, Salonen RO, Koistinen K, et al. Population exposure to fine particles and estimated excess mortality in Finland from an East European wildfire episode. J Expo Sci Environ Epidemiol 2009; 19: 414-422.

86 Mirabelli MC, Kunzli N, Avol E, et al. Respiratory symptoms following wildfire smoke exposure: airway size as a susceptibility factor. Epidemiology 2009; 20: 451-459.

87 Ovadnevaite J, Kvietkus K, Marsalka A. 2002 summer fires in Lithuania: impact on the Vilnius city air quality and the inhabitants health. Sci Tot Environ 2006; 356: 11-21.

88 Grumm RH. The central European and Russian heat event of July-August 2010. BAMS 2010; 92: 1285-1296.

89 Azevedo JM, Gonçalves FL, de Fátima Andrade M. Long-range ozone transport and its impact on respiratory and cardiovascular health in the north of Portugal. Int J Biometeorol 2011; 55: 187-202.

90 Henderson SB, Brauer M, Macnab YC, et al. Three measures of forest fire smoke exposure and their associations with respiratory and cardiovascular health outcomes in a population-based cohort. Environ Health Perspect 2011; 119: $1266-1271$.

91 de Longueville F, Ozer P, Doumbia S, et al. Desert dust impacts on human health: an alarming worldwide reality and a need for studies in West Africa. Int J Biometeorol 2013; 57: 1-19. 
92 Schwartz J, Norris G, Larson T, et al. Episodes of high coarse particle concentrations are not associated with increased mortality. Environ Health Perspect 1999; 107: 339-342.

93 Karanasiou A, Moreno N, Moreno T, et al. Health effects from Sahara dust episodes in Europe: literature review and research gaps. Environ Int 2012; 47: 107-114.

94 Niemi JV, Saarikoski S, Aurela M, et al. Long-range transport episodes of fine particles in southern Finland during 1999-2007. Atmospheric Environment 2009; 43: 1255-1264.

95 Perez L, Tobias A, Querol X, et al. Coarse particles from Saharan dust and daily mortality. Epidemiology 2008; 19 : 800-807.

96 Jiménez E, Linares C, Martínez D, et al. Role of Saharan dust in the relationship between particulate matter and short-term daily mortality among the elderly in Madrid (Spain). Sci Total Environ 2010; 408: 5729-5736.

97 Mallone S, Stafoggia M, Faustini A, et al. Saharan dust and associations between particulate matter and daily mortality in Rome, Italy. Environ Health Perspect 2011; 119: 1409-1414.

98 Samoli E, Kougea E, Kassomenos P, et al. Does the presence of desert dust modify the effect of PM10 on mortality in Athens, Greece? Sci Total Environ 2011a; 409: 2049-2054.

99 Tobías A, Pérez L, Díaz J, et al. Short-term effects of particulate matter on total mortality during Saharan dust outbreaks: a case-crossover analysis in Madrid (Spain). Sci Total Environ 2011; 412: 386-389.

100 Zauli Sajani S, Miglio R, Bonasoni P, et al. Saharan dust and daily mortality in Emilia-Romagna (Italy). Occup Environ Med 2011; 68: 446-451.

101 Alessandrini E, Stafoggia M, Faustini A, et al. Il ruolo delle sabbie Sahariane nell'associazione tra le polveri sottili e i ricoveri ospedalieri a Roma [The role of Saharan dust in the association between fine particles and hospital admissions in Rome.]. Epidemiol Prev 2012; 36: Suppl. 5, 30.

102 Díaz J, Tobías A, Linares C. Saharan dust and association between particulate matter and case-specific mortality: a case-crossover analysis in Madrid (Spain). Environ Health 2012; 11: 11.

103 Perez L, Tobías A, Querol X, et al. Saharan dust, particulate matter and cause-specific mortality: a case-crossover study in Barcelona (Spain). Environ Int 2012; 48: 150-155.

104 Thalib L, Al-Taiar A. Dust storms and the risk of asthma admissions to hospitals in Kuwait. Sci Total Environ 2012; 433: 347-351.

105 Olivieri D, Scoditti E. Impact of environmental factors on lung defences. Eur Respir Rev 2005; 14: 51-56.

106 Wang T, Chiang ET, Moreno-Vinasco L, et al. Particulate matter disrupts human lung endothelial barrier integrity via ROS- and p38 MAPK-dependent pathways. Am J Respir Cell Mol Biol 2010; 42: 442-449.

107 Clary-Meinesz CF, Cosson J, Huitorel P, et al. Temperature effect on the ciliary beat frequency of human nasal and tracheal ciliated cells. Biol Cell 1992; 76: 335-338.

108 Eccles R. An explanation for the seasonality of acute upper respiratory tract viral infections. Acta Otolaryngol 2002; 122: $183-191$.

109 Larsson K, Tornling G, Gavhed D, et al. Inhalation of cold air increases the number of inflammatory cells in the lungs in healthy subjects. Eur Respir J 1998; 12: 825-830.

110 Amirav I, Plit M. Temperature and humidity modify airway response to inhaled histamine in normal subjects. Am Rev Respir Dis 1989; 140: 1416-1420.

111 Koskela H, Tukiainen H. Facial cooling, but not nasal breathing of cold air, induces bronchoconstriction: a study in asthmatic and healthy subjects. Eur Respir J 1995; 8: 2088-2093.

112 Keatinge WR. Winter mortality and its causes. Int I Circumpolar Health 2002; 61: 292-299.

113 Kenny GP, Yardley J, Brown C, et al. Heat stress in older individuals and patients with common chronic diseases. CMAJ 2010; 182: 1053-1060.

114 Hsi-Hsing Y, Ching-Ping C, Juei-Tang C, et al. Inhibition of acute lung inflammation and injury is a target of brain cooling after heatstroke injury. J Trauma 2010; 69: 805-812.

115 el-Kassimi FA, Al-Mashhadani S, Abdullah AK, et al. Adult respiratory distress syndrome and disseminated intravascular coagulation complicating heat stroke. Chest 1986; 90: 571-574.

116 Jin Y, Hu Y, Han D, et al. Chronic heat stress weakened the innate immunity and increased the virulence of highly pathogenic avian influenza virus H5N1 in mice. J Biomed Biotechnol 2011; 2011: 367846.

117 Aitken ML, Marini JJ, Culver BH. Humid air increases airway resistance in asthmatic subjects. West J Med 1988; 149: 289-293.

118 Eschenbacher WL, Moore TB, Lorenzen TJ, et al. Pulmonary responses of asthmatic and normal subjects to different temperature and humidity conditions in an environmental chamber. Lung 1992; 170: 51-62.

119 Arantes-Costa FM, Zoriki S, Santos MH, et al. Effects of ventilation, humidity and temperature on airway responsiveness to methacholine in rats. Eur Respir J 2002; 19: 1008-1014.

120 D'Amato G, Liccardi G, D'Amato M, et al. Outdoor air pollution, climatic changes and allergic bronchial asthma. Eur Respir J 2002; 20: 763-776.

121 D’Amato G, Cecchi L. Effects of climate change on environmental factors in respiratory allergic diseases. Clin Exp Allergy 2008; 38: 1264-1274.

122 Gordon CJ. Role of environmental stress in the physiological response to chemical toxicants. Environ Res 2003; 92: $1-7$.

123 Leon LR. Thermoregulatory responses to environmental toxicants: the interaction of thermal stress and toxicant exposure. Toxicol Appl Pharmacol 2008; 233: 146-161.

124 Peng RD, Dominici F, Pastor-Barriuso R, et al. Seasonal analyses of air pollution and mortality in 100 US cities. Am J Epidemiol 2005; 161: 585-594.

125 Ito K, Thurston GD, Silverman RA. Characterization of PM2.5, gaseous pollutants, and meteorological interactions in the context of time-series health effects models. J Expo Sci Environ Epidemiol 2007; 17: S45-S60.

126 Hetland RB, Cassee FR, Låg M, et al. Cytokine release from alveolar macrophages exposed to ambient particulate matter: heterogeneity in relation to size, city and season. Part Fibre Toxicol 2005; 2: 4.

127 Stafoggia M, Forastiere F, Michelozzi P, et al. Summer temperature-related mortality: effect modification by previous winter mortality. Epidemiology 2009; 20: 575-583.

128 Keeler GJ, Dvonch T, Yip FY, et al. Assessment of personal and community-level exposures to particulate matter among children with asthma in Detroit, Michigan, as part of Community Action Against Asthma (CAAA). Environ Health Perspect 2002; 110: Suppl. 2, 173-181. 

collected during long-range transport of wildfire smoke to Helsinki. Toxicol Appl Pharmacol 2006; 215: 341-353.

130 Summary for Policymakers. In: Climate Change 2007: Impacts, Adaptation and Vulnerability. Contribution of Working Group II to the Fourth Assessment Report of the Intergovernmental Panel on Climate Change. Parry ML, Canziani OF, Palutikof JP, et al., eds. Cambridge, Cambridge University Press, 2007; pp. 7-22.

131 Kovats RS, Hajat S. Heat stress and public health: a critical review. Annu Rev Public Health 2008; $29: 41-55$.

132 Healy JD. Excess winter mortality in Europe: a cross country analysis identifying key risk factors. J Epidemiol Community Health 2003; 57: 784-789.

133 Rudge J, Gilchrist R. Excess winter morbidity among older people at risk of cold homes: a population-based study in a London borough. J Public Health 2005; 27: 353-358.

134 Wilkinson P, Pattenden S, Armstrong B, et al. Vulnerability to winter mortality in elderly people in Britain: population based study. BMJ 2004; 329: 647.

135 Donaldson GC, Keatinge WR. Cold related mortality in England and Wales; influence of social class in working and retired age groups. J Epidemiol Community Health 2003; 57: 790-791.

136 Zeka A, Zanobetti A, Schwartz J. Individual-level modifiers of the effects of particulate matter on daily mortality. Am J Epidemiol 2006; 163: 849-859.

137 Forastiere F, Stafoggia M, Berti G, et al. Particulate matter and daily mortality: a case-crossover analysis of individual effect modifiers. Epidemiology 2008; 19: 571-580.

138 Ren C, Melly S, Schwartz J. Modifiers of short-term effects of ozone on mortality in eastern Massachusetts-a casecrossover analysis at individual level. Environ Health 2010; 9: 3.

139 Medina-Ramón M, Schwartz J. Who is more vulnerable to die from ozone air pollution? Epidemiology 2008; 19: 672-679.

140 ASL RM-E Department of Epidemiology. Med-Particles. Particles size and composition in Mediterranean countries: geographical variability and short-term health effects. www.epidemiologia.lazio.it/medparticles/index. php/en/ Date last accessed: June 28, 2013.

141 Mannino DM, Buist AS. Global burden of COPD: risk factors, prevalence, and future trends. Lancet 2007; 370: 765-773.

142 McMichael AJ, Woodruff RE, Hales S. Climate change and human health: present and future risks. Lancet 2006; 367: 859-869.

143 Haines A, McMichael AJ, Smith KR, et al. Public health benefits of strategies to reduce greenhouse-gas emissions: overview and implications for policy makers. Lancet 2009; 374: 2104-2114.

144 Colette A, Koelemeijer R, Mellios G, et al. Cobenefits of Climate and Air Pollution Regulations. The Context of the European Commission Roadmap for Moving to a Low Carbon Economy in 2050. ETC/ACM Technical Paper 2011/ 20. Bilthoven, European Topic Centre on Air Pollution and Climate Change Mitigation, 2012.

145 Benchmarking Working Europe 2012. Brussels, European Trade Union Institute, 2012.

146 McMichael AJ. The urban environment and health in a world of increasing globalization: issues for developing countries. Bull World Health Organ 2000; 78: 1117-1126.

147 Forastiere F. Climate change and health: a challenge for epidemiology and public health. Int J Public Health 2010; 55: $83-84$ 